\title{
Why drug shortages are an ethical issue
}

\author{
Wendy Lipworth ${ }^{1,2}$ and Ian Kerridge ${ }^{2,3}$
}

1. Australian Institute of Health Innovation, University of New South Wales

2. Centre for Values, Ethics and the Law in Medicine, University of Sydney

\section{Royal North Shore Hospital, Sydney}

\section{REVIEW}

Please cite this paper as: Lipworth W, Kerridge I. Why drug shortages are an ethical issue. AMJ 2013, 6, 11, 556-559. http://doi.org/10.21767/AMJ.2013.1869
Corresponding Author:
Wendy Lipworth
Australian Institute of Health Innovation, AGSM Building, University of New South Wales, NSW 2052 Australia Email:w.lipworth@unsw.edu.au

\begin{tabular}{l} 
Abstract \\
\hline Drug shortages are a growing problem in developed \\
countries. To some extent they are the result of technical \\
and organisational failures, but to view drug shortages \\
simply as technical and economic phenomena is to miss the \\
fact that they are also ethical and political issues. This \\
observation is important because it highlights both the \\
moral and political imperative to respond to drug shortages \\
as vigorously as possible, and the need for those addressing \\
shortages to do so in ethically and politically sophisticated \\
ways. This brief article outlines the ethical issues that need \\
to be considered by anyone attempting to understand or \\
address drug shortages. \\
Key Words \\
Drug shortages, ethics, society, social consequence
\end{tabular}

\section{Introduction}

Drug shortages are an increasing problem in developed countries. The number of drugs that are affected by shortages have increased, as have the duration of shortages, the number of manufacturers involved in shortages, and the number of therapeutic classes affected. ${ }^{1,2}$ Many technical and organisational causes of drug shortages have been identified, relating to the ways in which medicines are manufactured, regulated, paid for and used by clinicians. ${ }^{3,4}$
To view drug shortages simply as technical and economic phenomena is, however, to miss the fact that they are also ethical and political issues. By this we mean two things: first, when they arise, drug shortages threaten the capacity for clinicians and governments to fulfil their moral obligations to patients and society-specifically, to provide benefit and minimise harm and to promote equity. Second, drug shortages stem from our societal values-in particular from the choices we have made about what we want most from our pharmaceutical and biotechnology industries, our regulators and our health services. These observations are important because they highlight both the moral and political imperative to respond to drug shortages as vigorously as possible, and the need for those addressing shortages to do so in ethically and politically sophisticated ways.

In this article, we describe the ethical dimensions of drug shortages and discuss the need for those wanting to prevent drug shortages to be aware of the moral trade-offs involved in any "solution".

\section{How drug shortages challenge the delivery of ethical health care}

How drug shortages challenge the delivery of "beneficent" and "non-maleficent" health care

With respect to beneficence and non-maleficence, there is now compelling evidence that individual patients, whole populations and health systems can be harmed by drug shortages. Individual patients can be harmed if there is no (equally) effective alternative therapeutic agent available to them as their care may be compromised, delayed or completely precluded. Patients can also be harmed if alternative agents have unexpected or unmanageable side effects. Further, medication errors are more likely to occur when clinicians and patients have to use less familiar medicines. $^{2,5-8}$

More generally, institutions and governments may feel compelled to trade-off safety against access by, for example, allowing re-use of single-vials, allowing expired 
drugs to be used, allowing companies to use sub-standard or unapproved manufacturing processes, purchasing compounded or imported medicines that may be of poor quality or even counterfeit, or expediting regulatory approval of new medicines. ${ }^{2,3,9-12}$

In addition to harming individual patients, drug shortages are a threat to public health. Indeed, others have described drug shortages as a "public health crisis" because they threaten our ability to prevent and treat both acute and chronic diseases. ${ }^{9(\mathrm{p} 42)}$ This is perhaps most obvious in the context of infectious diseases, where recent drug shortages of potentially major public health significance include shortages of several antimicrobial agents (increasing the risk of resistance and spread of diseases), ${ }^{8,13,14}$ shortages of purified protein derivative (PPD) tuberculin, which is used to detect tuberculosis infection; ${ }^{15}$ and shortages of several routine childhood vaccines including Haemophilus influenza type $b$ (Hib), diphtheria and tetanus toxoids and acellular pertussis, measles, mumps and rubella, and pneumococcal vaccines. ${ }^{16}$

With this in mind, it has been recognised that those making decisions about allocating resources need to "broaden (their) ethics analysis to reach beyond individually focused principles such as autonomy, beneficence, and nonmaleficence, to values focused on the common good, such as solidarity, communal beneficence and stewardship". ${ }^{9\left(p^{422}\right)}$

Drug shortages also threaten the development of evidence and the practice of evidence-based medicine by impeding clinical research, with trials being made smaller, modified or halted altogether ${ }^{17}$ and by making it difficult for clinicians to follow evidence-based clinical practice guidelines. ${ }^{18,20}$

Finally, drug shortages harm health systems as they lead to governments and organisations having to commit significant resources to overseeing and managing the situation, and potentially paying more for alternative medications than they would normally spend. ${ }^{6,10,11,21}$ These expenses all have opportunity costs for patients and the community.

How drug shortages challenge the delivery of "just" health care

In many cases, drug shortages force pharmacists and clinicians to make difficult choices between patients in the allocation of scarce resources. In some cases, priority needs to be given to those who are youngest or most ill, whose diseases are progressing most rapidly, who are most likely to benefit from therapy and/or who are on clinical trials. ${ }^{5,9,19}$ Where such differentiation cannot be achieved, then "principled" decisions cannot easily be made to privilege one group over another, and other measures such as random allocation may be needed. ${ }^{9}$

The need for such triage, and its ethical implications, has been recognised by many organisations, which have attempted to develop guidelines for resource allocation in the setting of drug shortages. These guidelines have tended to emphasise the need for procedural integrity and justice, engaging all stakeholders-including clinicians, patients and managers -in decisions about how scarce resources should be allocated, and aiming for consistency, objectivity, transparency, accountability and clear methods for communicating decisions (for examples see references 9, $17,19,22-24)$. It has also been noted that organisations have an ethical obligation to prepare for drug shortages by conserving supplies and by ensuring that the organisation is ready to respond to any shortage that arises. ${ }^{9}$

Finally, drug shortages do not affect all groups of patients to the same extent. Certain drug classes are particularly vulnerable to drug shortages, including central nervous system agents, anti-infective agents, cardiovascular drugs, dermatology drugs, gastrointestinal drugs, hormones and synthetic substitutes, electrolytic, caloric and water balance agents, and cancer medicines. ${ }^{1}$ This means that some of the most disadvantaged populations, such as critically ill patients, ${ }^{17,18}$ or patients with rare metabolic diseases, ${ }^{5}$ are most likely to face the additional burden of drug shortages, thus increasing already existing inequities in health care delivery.

\section{Ethics and the aetiology and prevention of drug shortages}

The literature on the causes of drug shortages has two key threads. On the one hand, there is discussion of how the pharmaceutical industry fails to fulfil its responsibilities to patients, clinicians and society ("industry misconduct"). On the other hand, there is a focus on economic and regulatory processes that make drug shortages more likely ("systemic issues").

\section{Industry misconduct}

With respect to the conduct of the pharmaceutical industry, it has been argued that the industry has been negligent by ceasing production of important medicines, by allowing its manufacturing processes to fail (or to "just pass") regulatory review, by taking advantage of the fact that purchasers of medicines assume that they are of high quality and may not be able to choose their suppliers, by deliberately failing to inform regulators and clinicians of impending drug shortages and by stockpiling drugs and reselling them much more expensively. ${ }^{2,4,10,11,25,26}$ 


\section{Systemic issues}

In contrast to this focus on industry misconduct, others with an interest in the causes of drug shortages have focused more on systemic issues. Shortages of generic injectable medicines in the United States, for example, are seen to stem from a combination of complex manufacturing processes that are vulnerable to quality control problems, reliance on only a few generic manufacturers with very little redundancy or flexibility in the manufacturing system, and low and competitive prices for generic drugs, placing pressure on producers to lower production costs, reduce inventories, outsource production and even stop manufacturing these medicines altogether-all of which increase the risk of drug shortages occurring. ${ }^{2-4,27}$ The relationship between regulatory processes and drug shortages is more contentious, and there is a debate as to whether regulatory actions (or lack thereof) have contributed to drug shortages. ${ }^{3,28}$

While this second thread (with its focus on systemic failings) might seem less morally charged than the first (with its focus on industry misconduct), it is important to bear in mind that these systemic failings are themselves the result of what we, as a society, have decided that we want from our industries, our governments, and our health systems. We have, for example, decided to value access to affordable generic medicines, to allow our industries the freedom to decide what they do and do not manufacture and how they distribute these goods, and to strike a certain balance between aggressiveness and leniency in our regulatory processes. ${ }^{3,27}$ While these value priorities have no doubt promoted both commercial innovation and access to affordable medicines, they also contribute to drug shortages.

Our willingness, as a society, to trust capitalism and "let markets work" has arguably also contributed to a number of perverse incentives that increase the likelihood of drug shortages. There are, for example, now merged companies that produce and market both branded products and generic versions of these brands. This creates an incentive to decrease generic production and shift demand towards more profitable brands. ${ }^{27}$ And by making generic medicines increasingly cheap, we are arguably driving manufacturers to seek lower cost production methods and production sites, thus increasing the risk of manufacturing problems and drug shortages. ${ }^{3,27}$ As Schweitzer argues:

"If profits were low enough and the likelihood of being inspected and "caught" producing unsafe products were low enough, it could be a profit-maximising strategy to produce just at, or even below, the minimum acceptable level-and accept the consequences (as rarely as they occur) as another cost of doing business". ${ }^{27(p 3)}$

It is an open question whether these behaviours represent unethical conduct, or simply "rational" behaviour in a market system. Either way, however, our value-laden social, political and economic choices are obviously contributing to drug shortages.

\section{Conclusion}

Drug shortages are a major threat to the delivery of beneficent, non-maleficent and equitable health care. There is, therefore, a moral imperative to prevent further drug shortages. Indeed, it has been argued that drug shortages are "life-threatening public health problems" that "impose moral imperatives on the individuals and organisations with the capabilities to affect them". ${ }^{29(p 144)}$

But drug shortages stem in part from choices that we, as a society, have made about how we want to organise our markets, our regulatory systems and our health services. If, therefore, we want to prevent drug shortages, we need to be aware that any proposed solution will likely threaten the values of one or more stakeholder groups, and will demand moral trade-offs. As Schweitzer notes:

"Solving the problem [of drug shortages] will present difficult choices within our health system. The choices will be difficult because required changes will entail reordering priorities". $^{27(p 1)}$

Importantly, because drug shortages are not simply a "pharmaceutical" or "medical" problem, but arise as a consequence of the way that we organise our markets and systems of both science and health, strategies to address them will likely require fundamental political and economic reform. As others have noted, addressing drug shortages will require "strong action" to promote legislative change, as well as local and international cooperation, transparency and accountability among stakeholders (including clinicians, policymakers, regulators, payers, patients and manufacturers) in both the prevention and management of drug shortages. ${ }^{1,2,7,9,12,21,28,29}$ Unless value conflicts are explicitly acknowledged and managed, such cooperation is likely to be thwarted.

\section{References}

1. Barthelemy I, Lebel D, Bussieres J-F. Drug shortages in health care institutions: perspectives in early 2013. Can J Hosp Pharm. 2013;66(1):39-40. 
2. Menees SB, Vargo JJ, Bonta C, Mayo L, Jacobson BC. Drug shortages in America: what about the gastroenterologist? Gastrointest Endosc. 2013;77(4):641-5.

3. Kweder SL, Dill S. Drug shortages: the cycle of quantity and quality. Clin Pharmacol Ther. 2013;93(3):245-51.

4. Woodcock J, Wosinska M. Economic and technological drivers of generic sterile injectable drug shortages. Clin Pharmacol Ther. 2013;93(2):170-6.

5 Linthorst GE, Burlina AP, Cecchi F, Cox TM, Fletcher JM, Feldt-Rasmussen U, Giugliani R, Hollak CE, Houge G, Hughes D, Kantola I, Lachmann R, Lopez M, Ortiz A, Parini R, Rivera A, Rolfs A, Ramaswami U, Svarstad E, Tondel C, TylkiSzymanska A, Vujkovac B, Waldek S, West M, Weidemann F, Mehta A. Recommendations on reintroduction of agalsidase Beta for patients with fabry disease in Europe, following a period of shortage. JIMD Rep. 2013;8:51-6.

6. Krisl JC, Fortier CR, Taber DJ. Disruptions in the supply of medications used in transplantation: implications and management strategies for the transplant clinician. Am J Transplant. 2013;13(1):20-30.

7. Lynas K. Patient care and health compromised by drug shortages in Canada: survey of physicians and pharmacists. Can Pharm J. 2013;146(2):67-8.

8. Gundlapalli AV, Beekmann SE, Graham DR, Polgreen PM, and on behalf of the Infectious Diseases Society of America's Emerging Infections Network. Perspectives and concerns regarding antimicrobial agent shortages among infectious disease specialists. Diagn Microbiol Infect Dis. 2013;75(3):256-9.

9. Singleton R, Chubbs K, Flynn J, Kaposy C, Peckham G, Penney J, Pullman D. From framework to the frontline: designing a structure and process for drug supply shortage planning. Healthc Manage Forum. 2013Spring;26(1):41-5.

10. Barlas S. FDA strategies to prevent and respond to drug shortages: finding a better way to predict and prevent company closures. P T. 2013;38(5):261-3.

11. Fox ER, Tyler LS. Call to action: finding solutions for the drug shortage crisis in the United States. Clin Pharmacol Ther. 2013;93(2):145-7.

12. Houston $P$, Chisholm R. Water, water everywhere, but not a drop in sight: the impact of drug shortages on Canadian anesthesia care. Can J Anaesth. 2013;60(6):51922.

13. Centers for Disease Control and Prevention (CDC). Impact of a shortage of first-line antituberculosis medication on tuberculosis control - United States, 2012-

2013. MMWR Morb Mortal Wkly Rep. 2013 May 24;62(20):398-400.

14. TB drug shortage forces control programs to make onerous choices. JAMA. 2013;310(2):135.
15. Jereb J, Mase S, Chorba T, Castro K. National shortage of Purified-Protein Derivative Tuberculin products. MMWR Morb Mortal Wkly Rep. 2013;62(16):312.

16. Fairbrother G, Donauer S, Staat MA, Broder K, Salisbury $S$, Morrow AL, Tabangin ME, Altaye $M$, Holloway $M$, Schwartz B. Cincinnati pediatricians' measured and reported immunizing behavior for children during the national shortages of pneumococcal conjugate vaccine. Vaccine. 2013;31(17):2177-83.

17. Rider AE, Templet DJ, Daley MJ, Shuman C, Smith LV. Clinical dilemmas and a review of strategies to manage drug shortages. J Pharm Pract. 2013;26(3):183-91.

18. Daley MJ, Lat I, Kane-Gill SL. Applicability of guideline recommendations challenged in the setting of drug shortages. Crit Care Med. 2013;41(7):E143-E4.

19. Valgus J, Singer EA, Berry SR, Rathmell WK. Ethical challenges: managing oncology drug shortages. J Oncol Pract. 2013;9(2):e21-3.

20. Barr J. Applicability of guideline recommendations challenged in the setting of drug shortages: reply. Crit Care Med. 2013;41(7):E144-E5.

21. Huys I, Simoens S. European drug shortages: a call for action! Int J Pharm Pract. 2013;21(1):1-2.

22. Rosoff PM, Patel KR, Scates A, Rhea G, Bush PW, Govert JA. Coping With critical drug shortages: an ethical approach for allocating scarce resources in hospitals. Arch Intern Med. 2012;172(19):1494-9.

23. Fox ER, Birt A, James KB, Kokko H, Salverson S, Soflin DL. ASHP guidelines on managing drug product shortages in hospitals and health systems. Am J Health Syst Pharm. 2009;66(15):1399-406.

24. Gibson JL, Bean S, Chidwick P, Godkin D, Sibbald RW, Wagner F. Ethical framework for resource allocation during a drug supply shortage. Healthc Q.2012;15(3):26-35.

25. Kuehn BM. Despite curbing new drug shortages, shortfall of drugs a persistent problem. JAMA. 2013;309(6):532-3.

26. Gupta DK, Huang SM. Drug shortages in the United States: a critical evaluation of root causes and the need for action. Clin Pharmacol Ther. 2013;93(2):133-5.

27. Schweitzer SO. How the US Food and Drug Administration can solve the prescription drug shortage problem. Am J Public Health. 2013;103(5):e10-4.

28. Bedard M. Drug shortages: can we resolve that problem? Can J Anaesth. 2013;60(6):523-7.

29. Teagarden JR, Epstein RS. Pharmacy benefit managers and their obligations during serious prescription drug shortages. Clin Pharmacol Ther. 2013;93(2):143-5.

\section{PEER REVIEW}

Commissioned, externally peer reviewed

\section{CONFLICTS OF INTEREST}

The authors declare that they have no competing interests. 